\title{
KAJIAN KEKERASAN DAN STRUKTUR MIKRO SAMBUNGAN LAS GMAW BAJA KARBON TINGGI DENGAN VARIASI MASUKAN ARUS LISTRIK
}

\author{
Wijoyo \\ Fakultas Teknologi Industri, Program Studi Teknik Mesin \\ Universitas Surakarta \\ Email: joyowi@yahoo.co.id \\ Bayu Kartiko Aji \\ Fakultas Teknologi Industri, Program Studi Teknik Mesin \\ Universitas Surakarta \\ Email: kartikaaji.bayu@yahoo.com
}

\begin{abstract}
ABSTRAK
Aplikasi sambungan las masih menjadi pilihan utama pada bidang konstruksi. Hal ini dikarenakan konstruksi menjadi ringan, murah dan cepat dalam proses pengerjaanya. Kekuatan las sangat dipengaruhi oleh komposisi dan sifat logam induk maupun logam pengisi, proses pengelasan, pemanasan serta adanya tegangan sisa. Tujuan penelitian ini adalah menyelidiki kekerasan dan struktur mikro sambungan las GMAW baja karbon tinggi akibat variasi masukan arus listrik. Penelitian menggunakan bahan baja AISI 1065 dan logam pengisi ER70S-6, dengan variasi arus listrik 80 A, 100 A dan 120 A. Kecepatan pengelasan adalah $5 \mathrm{~mm} / \mathrm{s}$, kecepatan logam pengisi $4 \mathrm{~mm} / \mathrm{s}$ dan tegangan DC $22 \mathrm{~V}$. Pengujian kekerasan dengan menggunakan mesin uji kekerasan rockwell, sedangkan foto mikro struktur menggunakan mikroskop optic. Hasil penelitian menunjukkan bahwa semakin tinggi arus listrik yang dipakai dalam pengelasan sampai $120 \mathrm{~A}$, maka kekerasan hasil lasan semakin menurun, sedangkan struktur mikro didominasi cementite dengan ukuran yang lebih halus.
\end{abstract}

Kata kunci: arus, GMAW, kekerasan, sturktur mikro.

\begin{abstract}
Applications welded joints are still the main choice in the field of construction. This is because the construction becomes lighter, cheaper and faster in the welding process. Weld strength is strongly influenced by the composition and properties of the based metal and filler, welding process, the heating and the presence of residual stress. The purpose of this study was to investigate the hardness and GMAW welding joint microstructure of high carbon steel due to variations in electrical current input. Research using AISI 1065 steel material and filler ER70S-6, with a variation of the electric current of $80 \mathrm{~A}, 100 \mathrm{~A}$ and 120 A. The welding speed is $5 \mathrm{~mm} / \mathrm{s}$, the speed of filler metal $4 \mathrm{~mm} / \mathrm{s}$ and a DC voltage of $22 \mathrm{~V}$. Hardness test using rockwell hardness testing machine, while the micro-structure photograph using an optical microscope. The results showed that the higher the electric current used in the welding up to 120 $A$, the hardness results of welds decreases, while the predominantly cementite microstructure with finer sizes.
\end{abstract}

Keywords: electric current, GMAW, hardness, micro structures.

\section{PENDAHULUAN}

Sambungan las banyak digunakan dengan pertimbangan bahwa konstruksi ringan, murah dan pengerjaan cepat. Perancangan las dan cara pengelasan harus betul-betul memperhatikan kesesuaian antara sifat-sifat las dengan kegunaan konstruksi serta keadaan disekitarnya [1]. Kekuatan sambungan las secara umum dipengaruhi oleh komposisi dan sifat logam yang dilas, komposisi dan sifat logam pengisi (elektroda), proses pengelasan, daerah pemanasan langsung, daerah yang terkena pengaruh panas dan adanya tegangan sisa.

Proses pengelasan adalah proses penyambungan dua bagian logam atau lebih dengan menggunakan energi panas. Energi panas pada pengelasan tersebut akan menimbulkan terjadinya siklus termal. Adanya siklus termal tersebut akan mengakibatkan terjadinya tegangan sisa, distorsi serta laju pendinginan pada logam las dan daerah sekitarnya. Struktur mikro logam las sangat dipengaruhi oleh laju pendinginan dan komposisi kimia bahan (logam induk dan elektroda). Pada akhirnya tegangan sisa dan struktur mikro 
logam las tersebut akan mempengaruhi sifat mekanis dari logam lasan, terutama terjadinya penurunan sifat fatik [2].

Heat input sangat berpengaruh terhadap struktur mikro logam las. Hal ini terjadi disebabkan oleh kuat arus yang besar akan meningkatkan masukkan panas sehingga memperlambat laju pendinginan. Peningkatan heat input meningkatkan jumlah prosentase ferit acicular dan ketangguhan sambungan las [3]. Preheat mempengaruhi struktur mikro hasil pengelasan, yaitu terbentuk struktur mikro berupa ferit batas butir. Kekuatan impak optimum pada suhu transisi $-15^{\circ}$ dan energinya sebesar 125 Joule pada preheat $100^{\circ} \mathrm{C}$ sambungan las GTAW baja A283C [4]. Ketangguhan impak HAZ pada baja HQ130 menurun dengan masukan panas las dari $9,2 \mathrm{~kJ} / \mathrm{cm} \mathrm{ke} 26,4 \mathrm{~kJ} / \mathrm{cm}$. Waktu pendinginan $\left(\mathrm{t}_{8 / 5}\right)$ antara $10-20$ detik pada masukan panas antara 13,1-18,6 kJ/cm meningkatkan ketangguhan HAZ hasil pengelasan GMAW baja HQ130 [5].

Nilai kekerasan zona HAZ lebih tinggi dari logam las dan logam dasar, hal ini disebabkan oleh jumlah fase austenit interdendritik yang tinggi dan tingkat pendinginan yang cepat pada butir daerah HAZ hasil pengelasan plat AISI $904 \mathrm{~L}$ stainless steel super austenitic dengan menggunakan las GMAW [6].

Hasil sambungan pengelasan logam AISI 304 \& 316 dengan las TIG \& las MIG adalah sebagai berikut: nilai kekerasan (BHN) di arus listrik 40 ampere untuk las TIG adalah 162,53 BHN, sedangkan pada las MIG adalah 196,54 BHN. Kekuatan tarik sambungan las TIG lebih tinggi dari sambungan las MIG, yaitu berturut-turut adalah: 675,22 MPa dan 652,029 N/mm² [7].

Las GMAW merupakan proses pengelasan busur listrik, dengan busur listrik diselimuti oleh gas di atas daerah pengelasan. Kawat las pengisi yang juga berfungsi sebagai elektroda diumpankan secara terus-menerus. Gas pelindung yang digunakan adalah Argon, Helium atau campuran dari keduanya. Untuk memantapkan busur kadang-kandang ditambahkan gas $\mathrm{O}_{2}$ antara $2-5 \%$ atau $\mathrm{CO}_{2}$ antara $5-20 \%$.

Masukan panas adalah besarnya energi panas tiap satuan panjang las ketika sumber panas bergerak. Besarnya masukan panas pada proses pengelasan adalah seperti pada persamaan (1) [8]:

$q=\frac{\eta E I}{v}$

dengan $: \mathrm{q}=$ masukan panas $(\mathrm{J} / \mathrm{mm}), \quad \mathrm{v}=$ kecepatan pengelasan $(\mathrm{mm} / \mathrm{s}), \eta=$ efisiensi, $E=$ potensial listrik (volt) dan I = arus listrik (ampere)

Proses pembekuan logam cair sangat sensitif terhadap kecepatan pendinginan. Pada umumnya waktu pendinginan (cooling time) antara temperatur $800^{\circ} \mathrm{C}-500^{\circ} \mathrm{C}$ dipakai sebagai acuan pada pengelasan baja karbon rendah, karena pada interval suhu tersebut terjadi transformasi fasa dari austenite menjadi ferrite atau bainite yang dipengaruhi oleh kecepatan pendinginannya. Struktur mikro baja yang terbentuk selama pendinginan antara temperatur $800^{\circ} \mathrm{C}-500^{\circ} \mathrm{C}\left(\Delta \mathrm{t}_{8 / 5}\right)$ ditentukan oleh laju pedinginan.

Waktu pendinginan dapat dihitung dari persamaan (2) berikut [8]:

$\Delta t_{8 / 5}=\frac{q / v}{2 \pi k}\left[\frac{1}{500-T_{0}}-\frac{1}{800-T_{0}}\right]$

dengan : $\Delta \mathrm{t}_{8 / 5}=$ waktu pendinginan antara temperatur $800^{\circ} \mathrm{C}-500^{\circ} \mathrm{C}(\mathrm{s}), \mathrm{k}=$ konduktifitas panas $(\mathrm{J} / \mathrm{mms}$ $\left.{ }^{1} \mathrm{~K}^{-1}\right)$ dan $\mathrm{T}_{0}=$ suhu awal $\left({ }^{\circ} \mathrm{C}\right)$

Tujuan penelitian ini adalah menyelidiki kekerasan dan struktur mikro sambungan las GMAW baja karbon tinggi akibat variasi masukan arus listrik.

\section{METODOLOGI}

\subsection{Bahan}

Bahan yang dipakai pada penelitian ini adalah baja AISI 1065 dan logam pengisi yang digunakan adalah ER70S-6 sedangkan gas yang digunakan adalah gas argon (Ar).

\subsection{Proses Pengelasan}

Pengelasan menggunakan pelat baja AISI 1065 dan filler ER70S-6. Pengelasan GMAW dilakukan dengan variasi arus $80 \mathrm{~A}, 100 \mathrm{~A}$ dan $120 \mathrm{~A}$, tegangan DC $22 \mathrm{~V}$ polarisasi terbalik (DCRP), debit gas argon 2,5 sampai $5 \mathrm{ltr} / \mathrm{menit}$, kecepatan pengelasan $5 \mathrm{~mm} / \mathrm{s}$ dan kecepatan kawat $4 \mathrm{~mm} / \mathrm{s}$. Tebal pelat yang digunakan adalah $10 \mathrm{~mm}$, alur las dibuat bentuk V ganda dengan sudut $70^{\circ}$ dan las multirun seperti 
terlihat pada Gambar 1. Dimensi plat adalah $300 \mathrm{~mm}$ x $100 \mathrm{~mm}$ x $10 \mathrm{~mm}$. Komposisi logam induk dan logam pengisi dapat dilihat pada Tabel 1 .

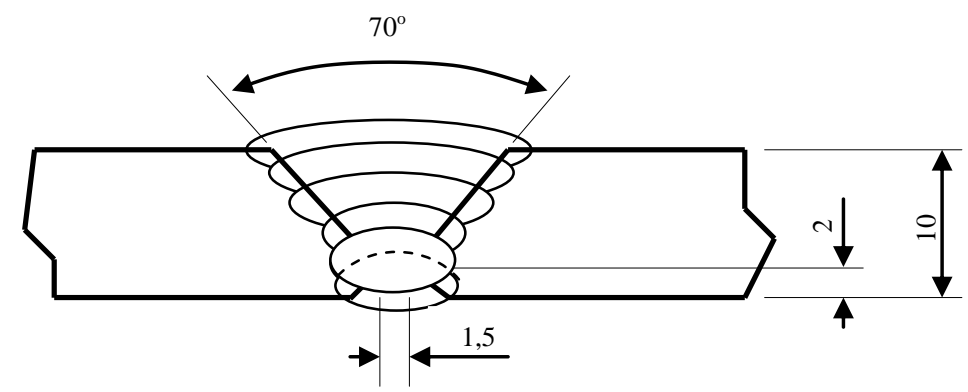

Gambar 1. Bentuk Alur Las

Tabel 1. Komposisi kimia logam induk dan logam pengisi dalam \% berat

\begin{tabular}{ccc}
\hline Unsur & AISI 1065 & ER70S-6 \\
\hline $\mathrm{Fe}$ & Balance & Balance \\
$\mathrm{C}$ & 0.693 & $0,06-0,15$ \\
$\mathrm{Si}$ & 0.254 & $0,8-1,15$ \\
$\mathrm{Mn}$ & 0.264 & $1,4-1,85$ \\
$\mathrm{P}$ & 0.033 & $0,025 \max$ \\
$\mathrm{S}$ & 0.003 & $0,035 \max$ \\
$\mathrm{Cr}$ & 0.084 & $0,15 \max$ \\
$\mathrm{Mo}$ & 0.153 & $0,15 \max$ \\
$\mathrm{Ni}$ & 0.335 & $0,15 \max$ \\
$\mathrm{Al}$ & 0.07 & - \\
$\mathrm{Co}$ & 0.082 & - \\
$\mathrm{Cu}$ & 0.188 & $0,50 \max$ \\
$\mathrm{Nb}$ & 0.098 & - \\
$\mathrm{Pb}$ & 0.0096 & - \\
$\mathrm{Sn}$ & 0.009 & - \\
$\mathrm{Ti}$ & 0.051 & - \\
$\mathrm{V}$ & 0.052 & \\
$\mathrm{~W}$ & 0.515 & - \\
\hline
\end{tabular}

\subsection{Pengujian}

Pengujian kekerasan menggunakan mesin uji kekerasan rockwell. Pengamatan struktur mikro pada masing-masing hasil las dengan variasi arus listrik yang diperoleh dari hasil foto mikro dengan menggunakan mikroskop optic.

\section{HASIL PENELITIAN DAN PEMBAHASAN}

\subsection{Pengujian Kekerasan}

Pengujian kekerasan dilakukan pada daerah las, HAZ dan logam induk. Nilai kekerasan pada daerah las paling tinggi disusul dengan HAZ dan logam induk. Data distribusi kekerasan hasil pengujian pada Gambar 2 menunjukkan kecederungan yang seragam pada tiap spesimen yaitu terjadi peningkatan nilai kekerasan pada daerah las dan selanjutnya menurun pada HAZ sampai logam induk.

Fokus penelitian ini adalah pada daerah las sehingga pembahasan mengenai pengujian kekerasan juga difokuskan pada daerah las. Gambar 3 menunjukkan perbandingan kekerasan sambungan las pada 
berbagai arus listrik. Pada las dengan variasi arus listrik 80 A, 100 A dan 120 A, mempunyai nilai kekerasan rata-rata logam las berturut-turut adalah: 62,67 HRC, 55,27 HRC dan 44,80 HRC. Dari hasil nilai kekerasan berbagai spesimen pada logam las tersebut disebabkan pada spesimen las dengan variasi arus listrik 80 A mengalami laju pendinginan yang cepat. Laju pendinginan yang cepat ini menyebabkan struktur mikro las yang terbentuk menjadi lebih kasar (cementite) dibanding struktur mikro las pada arus listrik yang lebih tinggi. Struktur mikro yang kasar ini (cementite) mempunyai sifat keras, ini ditunjukkan pada spesimen dengan arus listrik 80 A yang mempunyai nilai kekerasan paling tinggi, karena struktur mikronya paling kasar dan menurun pada spesimen las pada arus listrik $100 \mathrm{~A}$ dengan struktur mikro yang lebih halus. Sedangkan pada spesimen las dengan arus listrik 120 A, kekerasan lasannya paling rendah, hal ini disebabkan karena laju pendinginan yang lambat, sehingga material menjadi lunak.

Hasil ini sejalan dengan [3], [4] dan [5], bahwa peningkatan arus listrik akan meningkatkan heat input pada pengelasan yang berdampak pada memperlambat laju pendinginan dan peningkatan kekuatan sambungan las.

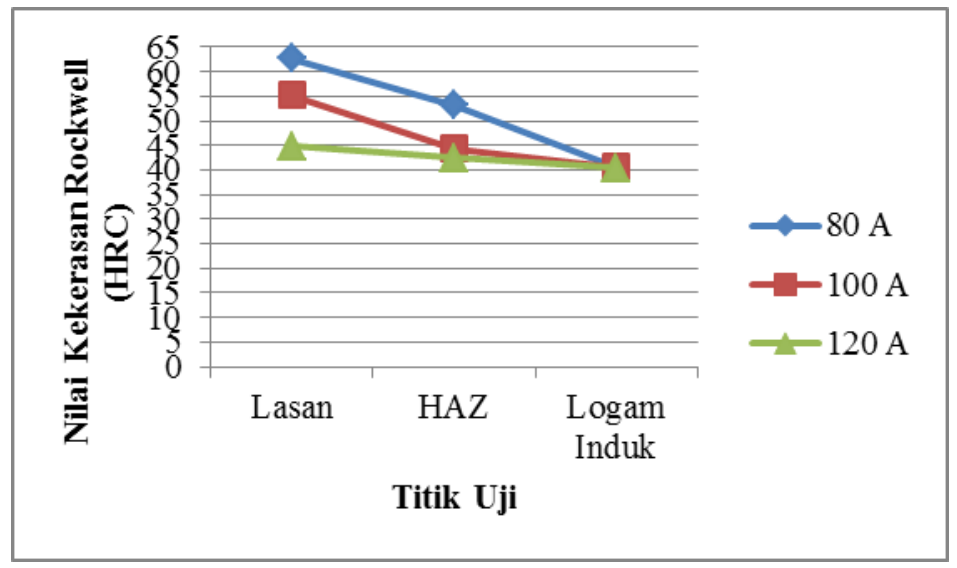

Gambar 2. Distribusi Kekerasan Rockwell

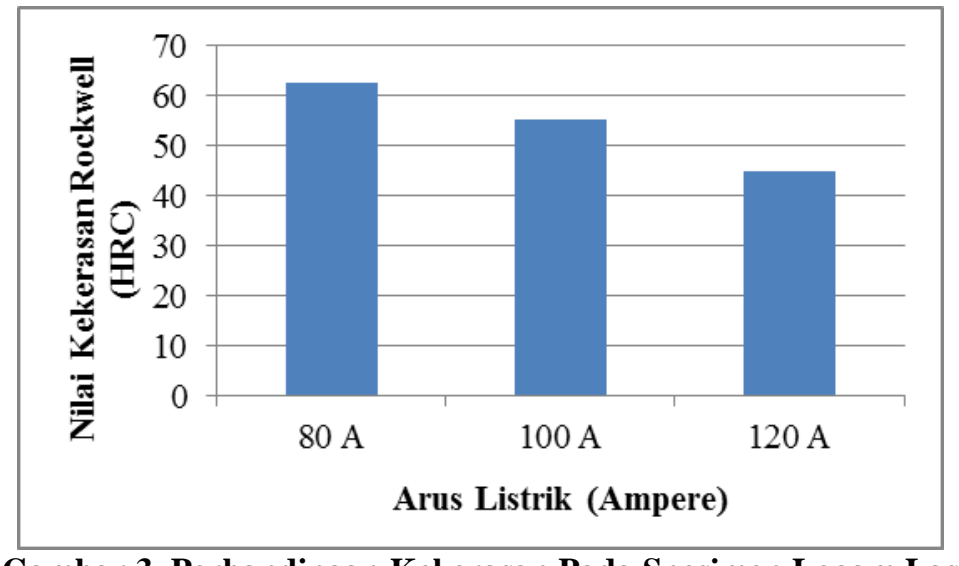

Gambar 3. Perbandingan Kekerasan Pada Spesimen Logam Las

\subsection{Pengamatan Struktur Mikro}

Pengamatan struktur mikro bertujuan untuk melihat apakah terjadi perubahan struktur mikro pada lasan dengan variasi arus listrik selama proses pengelasan. Pengamatan struktur mikro dilakukan pada ketiga spesimen dan diambil pada tiga titik dari raw material, daerah HAZ, dan daerah las. Dengan pembesaran gambar sampai 200x dan hasil foto struktur mikro dapat dilihat pada Gambar 4, 5 dan 6, dibawah ini:

Hasil foto mikro las menunjukkan adanya perbedaan. Secara keseluruhan struktur dari logam induk ( raw material) memiliki bentuk struktur mikro yang didominasi pearlite dan sedikit cementite yang menjadi ciri khas dari struktur mikro dari baja karbon tinggi. Pearlite adalah gabungan ferrite dan cementite berwarna gelap dan bersifat mampu mesin dan keras tetapi ulet. Sedangkan cementite mempunyai sifat yang keras.

Saat terjadinya pengelasan yang menyebabkan adanya siklus thermal (pemanasan dan pendinginan cepat), hal ini sangat berpengaruh terhadap daerah HAZ maupun daerah las. Pada daerah HAZ struktur 
mikro menjadi rusak dari logam induknya, yaitu struktur pearlite menjadi hancur menjadi butiran bentuk yang kasar. Daerah yang paling terpengaruh oleh siklus thermal adalah daerah las, pada daerah las terjadinya pencairan dan kemudian membeku secara cepat. Pada daerah las ini struktur mikronya lebih kecil/halus dan lebih rapat, dengan dominasi cementite dan pearlite semakin berkurang. Dari ketiga spesimen dengan arus listrik 80 A, 100 A dan 120 A, ukuran cementite-nya yang paling besar adalah pada arus listrik $80 \mathrm{~A}$, diikuti berturut-turut oleh arus listrik $100 \mathrm{~A}$ dan $120 \mathrm{~A}$. Bentuk ukuran struktur yang berbeda ini yang mengakibatkan kekuatan lasnya juga berbeda, yaitu seperti yang ditunjukkan pada hasil pengujian kekerasannya, spesimen las dengan arus listrik 80 A mempunyai kekerasan yang tertinggi.
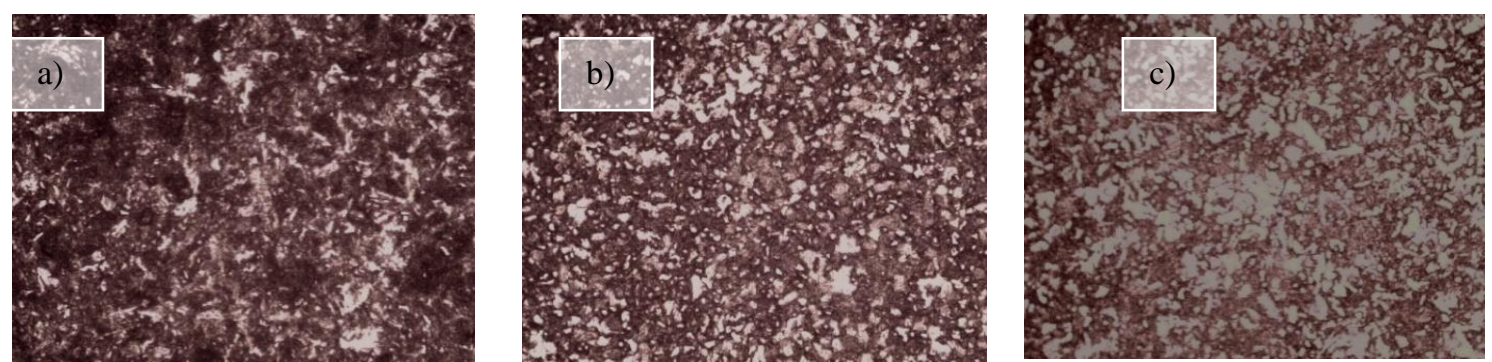

Gambar 4. Struktur Mikro Pada Arus Pengelasan 80 A: a) Logam Induk, b) HAZ, c) Logam Las
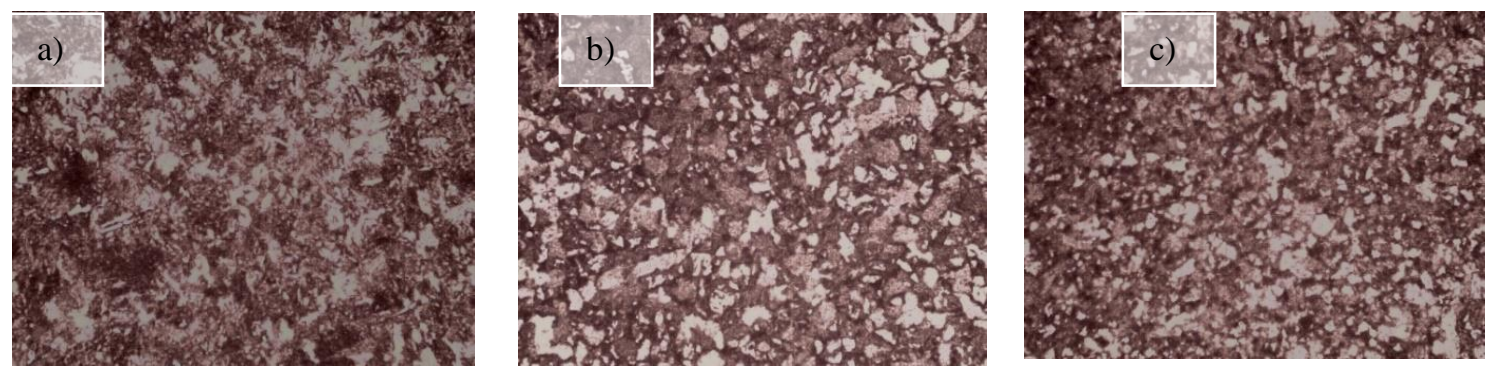

Gambar 5. Struktur Mikro Pada Arus Pengelasan 100 A: a) Logam Induk, b) HAZ, c) Logam Las
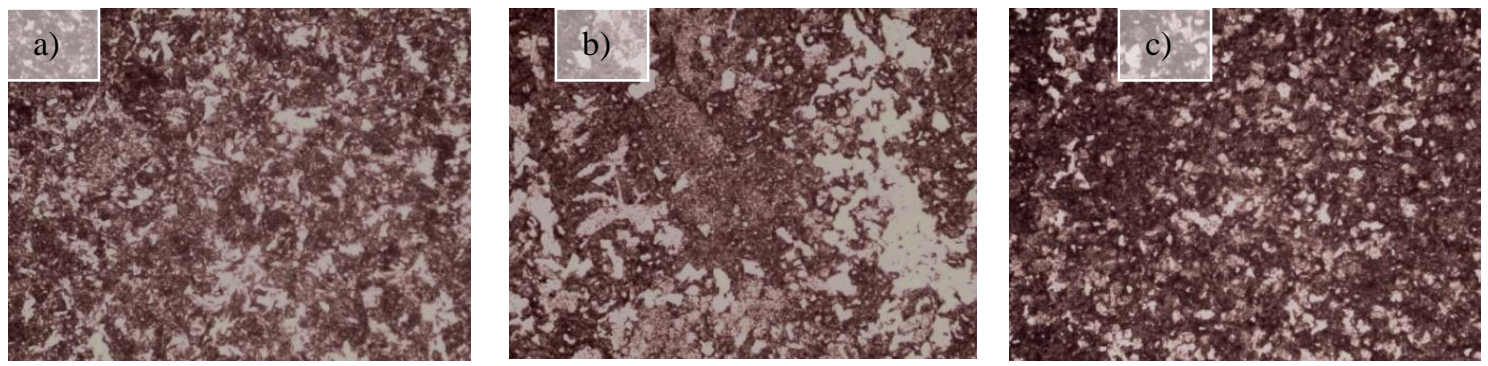

Gambar 6. Struktur Mikro Pada Arus Pengelasan 120 A: a) Logam Induk, b) HAZ, c) Logam Las

\section{KESIMPULAN}

1) Peningkatan arus listrik pada pengelasan dapat menurunkan kekerasan hasil las.

2) Semakin tinggi arus listrik yang digunakan dalam pengelasan baja karbon tinggi sampai $120 \mathrm{~A}$ akan menurunkan jumlah dan ukuran cementite, yang memiliki sifat keras.

3) Sifaf-sifat mekanis yang lain hasil pengelasan pada variasi pemakaian arus listrik sangat mungkin dipengaruhi oleh struktur mikro dan sifat keras dari hasil lasan tersebut.

\section{DAFTAR PUSTAKA}

[1] Wiryosumarto, H. dan Okumura, T. 1996. Teknologi Pengelasan Logam. Jakarta: PT. Pradya Paramita.

[2] Radaj, D. 1992. Heat effects of Welding : Temperature Field, Residual Stress, Distortion. Berlin: Springer-Verlag.

[3] Subekti, N. 2005. "Pengaruh Heat Input Terhadap Ketangguhan dan Struktur Mikro Pada Pengelasan Busur Terendam Pipa Spiral”. Simetris 4. 10-18. 
[4] Sembiring, A.S.F. et al. 2005. "Pengaruh Preheat Terhadap Struktur Mikro dan Ketangguhan Impak Sambungan Las GTAW Pada Pengelasan Baja A283C". Simetri 4. 1-9.

[5] Juang, W., et al. 2003. "Effect of Weld Heat Input on Toughness and Structure of HAZ of a New Super-high Strength Steel”. Indian Academy of Sciences 26. 3, 301-305.

[6] Sathiya P., et al. 2010. "Microstructural characteristics on bead on plate welding of AISI 904 L super austenitic stainless steel using Gas metal arc welding process". International Journal of Engineering, Science and Technology 2. 6, 189-199.

[7] Kumar L. S., et al. 2011. "Experimental Investigation for Welding Aspects of AISI 304 \& 316 by Taguchi Technique for the Process of TIG \& MIG Welding”. International Journal of Engineering Trends and Technology 2. Issue2, 28-33.

[8] Kou, S. 1987. Welding Metallurgy. New York: John Willey, Sons, Inc. 